\title{
Metrology for radiation protection: a new European network in the foundation phase
}

\author{
Annette Röttger ${ }^{1}$, Attila Veres ${ }^{2}$, Vladimir Sochor ${ }^{3}$, Massimo Pinto $^{4}$, Michal Derlacinski ${ }^{5}$, Mihail-Razvan Ioan ${ }^{6}$, \\ Amra Sabeta $^{7}$, Robert Bernat ${ }^{8}$, Christelle Adam-Guillermin ${ }^{9}$, João Henrique Gracia Alves ${ }^{10}$, Denis Glavič-Cindro ${ }^{11}$, \\ Steven Bell ${ }^{12}$, Britt Wens ${ }^{13}$, Linda Persson ${ }^{14}$, Miloš Živanović ${ }^{15}$, and Reetta Nylund ${ }^{16}$ \\ ${ }^{1}$ Physikalisch-Technische Bundesanstalt, Ionizing Radiation, Braunschweig, Germany \\ ${ }^{2}$ Commissariat à l'énergie atomique et aux énergies alternatives, Paris, France \\ ${ }^{3}$ Cesky Metrologicky Institut, Brno, Czech Republic \\ ${ }^{4}$ Agenzia Nazionale per le nuove tecnologie, l'energia e lo sviluppo economico sostenibile, \\ Istituto Nazionale di Metrologia delle Radiazioni Ionizzanti, Rome, Italy \\ ${ }^{5}$ Główny Urząd Miar, Warsaw, Poland \\ ${ }^{6}$ Institutul National de Cercetare-Dezvoltare pentru Fizica si Inginerie Nucleara "Horia Hulubei", Bucharest, Romania \\ ${ }^{7}$ Institut za mjeriteljstvo Bosne i Hercegovine, Sarajevo, Bosnia and Herzegovina \\ ${ }^{8}$ Ruđer Bošković Institute, Zagreb, Croatia \\ ${ }^{9}$ Institut de Radioprotection et de Sureté Nucléaire, Fontenay-aux-Roses, France \\ ${ }^{10}$ Instituto Superior Técnico (IST), LPSR - Laboratório de Metrologia das Radiações Ionizantes (LMRI), Lisboa, Portugal \\ ${ }^{11}$ Institut Jožef Stefan, Ljubljana, Slovenia \\ ${ }^{12}$ NPL Management Limited, Teddington, United Kingdom \\ ${ }^{13}$ Studiecentrum voor Kernenergie, Centre d'Etude de l'Energie Nucléaire, Brussels, Belgium \\ ${ }^{14}$ Strålsäkerhetsmyndigheten, Stockholm, Sweden \\ ${ }^{15}$ Vinca Institute of Nuclear Sciences - National Institute of the Republic of Serbia, University of Belgrade, Belgrade, Serbia \\ ${ }^{16}$ Säteilyturvakeskus, Helsinki, Finland
}

Correspondence: Annette Röttger (annette.roettger@ptb.de)

Received: 16 August 2021 - Revised: 20 October 2021 - Accepted: 25 October 2021 - Published: 17 November 2021

\begin{abstract}
More than 23 million workers worldwide are occupationally exposed to ionizing radiation and all people in the world are exposed to environmental radiation. The mean exposure, that is the mean annual dose of per person, is dominated by medical applications and exposure to natural sources. Due to recent developments in healthcare, e.g. the increasing application of ionising radiation in medical imaging with relative high doses like CT, and modern high dose applications (for example CT angiography), the exposure due to medical application has risen. Additionally, the changes in living conditions increase the exposure to natural radioactivity also: More living time is spent in buildings or in an urban environment, which causes higher exposure to Naturally Occurring Radioactive Materials (NORM) in building materials and higher exposure to radon. The level of radon activity concentration in buildings is far higher than in the en-
\end{abstract}

vironment (outdoor). This effect is often amplified by modern energy-efficient buildings which reduce the air exchange and thus increase the radon indoor activity concentration. In summary both medical application of ionizing radiation and natural sources are responsible for the increase of the mean annual exposure of the population.

The accurate measurement of radiation dose is key to ensuring safety but there are two challenges to be faced: First, new standards and reference fields are needed due to the rapid developments in medical imaging, radiotherapy and industrial applications. Second, direct communication channels are needed to ensure that information on best practice in measurements reaches effectively and quickly the people concerned.

It is therefore necessary to allow for an international exchange of information on identified problems and solutions. 
Consequently, a European Metrology Network (EMN) for radiation protection under the roof of EURAMET is in the foundation phase. This network EMN for Radiation Protection is being prepared by the project EMPIR 19NET03 supportBSS. The project aims to prepare this EMN by addressing this issue through the identification of stakeholder research needs and by implementing a long-term ongoing dialogue between stakeholders and the metrology community. The EMN will serve as a unique point of contact to address all metrological needs related to radiation protection and it will relate to all environmental processes where ionising radiation and radionuclides are involved.

A Strategic Research Agenda and two roadmaps are in development, covering the metrology needs of both the Euratom Treaty and the EU Council Directive 2013/59/EURATOM pinning down the basic safety standards for protection against the dangers arising from exposure to ionizing radiation. Furthermore, long-term knowledge sharing, and capacity building will be supported and a proposal for a sustainable joint European metrology infrastructure is under way. This will significantly strengthen the radiation protection metrology and support radiation protection measures. The final goal of the network project is a harmonised, sustainable, coordinated and smartly specialised infrastructure to underpin the current and future needs expressed in the European regulations for radiation protection.

\section{Introduction and motivation}

Radiation protection legislation has been revised to better protect European citizens Council Directive 2013/59/Euratom, 2013). A revision of the EURATOM Directive broadened its scope to cover all radiation sources and categories of exposure. Radiation-related risks to workers, patients, members of the public (IAEA, 2018; OECD, 2013), and the environment (IAEA, 2021; UNEP, 2016; UNSCEAR, 2008; Stanley et al., 2019) are now all included, partly in response to lessons learned from the Fukushima nuclear accident. Radiation protection measurements will need to become more responsive to changing needs, by supporting new technologies such as pulsed radiation in medical and technical applications, more harmonised in worker protection measures, and more supporting by the take up of digitalisation trends. As there is no comprehensive organisation capable of supporting all these requirements, a European Metrology Network for reliable radiation protection regulation is being considered. Its concept was approved by the General Assembly of EURAMET 2021 and the approved EMN for Radiation Protection was established by signature on 16 September 2021. EURAMET is the Regional Metrology Organisation (RMO) of Europe, the European association of national metrology institutes.
The project 19NET03 supportBSS to prepare the EMN for Radiation Protection was started in June 2020 for the duration of four years. It prepared the EMN for Radiation Protection to provide metrological solutions by addressing the stakeholders needs, either related to research or for metrological service. Therefore, the overall aim is to develop a long-term dialogue between the metrology community and relevant stakeholders in the field of radiation protection. The need for this development can be understood best by a reflection to the history of radiation protection. This history begins at the turn of the 20th century with the observation that ionizing radiation can have a damaging effect on living organisms. The discovery of X-rays by Wilhelm Conrad Röntgen in 1895 led to extensive experimentation by scientists, physicians and inventors. Initially, the experiments were handled very carelessly. For a long time, the dangers of radioactivity and radiation were not fully recognized (Clarke and Valentin, 2009; ICRP, 2009).

The history of radiation protection regulation in Europe (ICRP, 2009) was started by the EURATOM Treaty in 1957 (Södersten, 2018; EURATOM Treaty, 2021). The original purpose and driver of this development was to create a specialist market for nuclear power in Europe, by developing nuclear energy and distributing it to its member states. It covers a large variety of areas associated with nuclear power and ionising radiation as diverse as safeguarding of nuclear materials, radiation protection and construction of the International Fusion Reactor ITER. The feedback process on the following legislation turned out to be the most challenging. Various regulations were implemented whose metrological implications were not considered in detail. The implementation was done without asking feedback from the metrology institutes due to missing communication strategies. This generated social dissatisfaction with the implementation of hard-to-reach limit values for which two recent examples are given here: One example for this is the lowering of the exposure limit for the eye lens. As a consequence of this reduction the quantity $H_{p}(3)$ was included in radiation protection surveillance according to the German Strahlenschutzverordnung (StrlSchV, 2018). New dosemeters had to be developed, type tested and put to a mandatory surveillance service in nearly all German hospitals to protect the staff members. Though the intention is to better protect the staff, the acceptance is poor: The limits are not generally accepted by medical experts, the best wearing position of the dosemeter is under discussion and the additional costs must be covered by the hospitals.

Another recent example is the radiation protection against radon: The national reference levels for indoor radon activity concentration in dwellings and workplaces alike must be set below $300 \mathrm{~Bq} / \mathrm{m}^{3}$ and it is a requirement for all member states to have delineation of Radon priority areas (Bossew, 2018). This is a quite complex and costly action, because indoor radon activity concentration is subject to high spatial variability. This is due to the variability of the geogenic radon 
potential which in most cases is the main source of indoor radon. Additionally, the variability of the physical properties of buildings and the ventilation habits must be considered. Most member states and regional authorities were not able to fulfil the requirement in time. Nevertheless, the awareness of radon in the public has risen. The key to a successful implementation is a quality assured infrastructure to implement reliable measurements as a base for the dose assessment and remediations measures.

The need to implement this dialogue was observed and will be extended by collection of needs from stakeholders.

\section{Role of the European Metrology Network for Radiation Protection}

EURAMET's European Metrology Networks (EMNs) aim at realizing EURAMET's vision of building metrology capabilities based on high quality scientific research and an advanced metrology infrastructure. The EMNs coordinate the identified measurement needs and formulate the measurement services and research and knowledge transfer accordingly (Jarvis, 2018). In recent years, the EU's radiation protection regulations have become ever more complex due to stricter legal dose assessments, exposure and activity limits as well as reference levels for activity concentrations, technological developments and emerging complex practices.

New radiation practices and new technological developments have resulted in the use of radiation fields of growing complexity. Therefore, the metrology for radiation protection measurements and legal dose assessment is a highly complex task. It requires increased efforts in all member states to build up and maintain sustainable metrological competence. Increased digitalisation will lead to digital legal dosimetry over the next few years. Legal dose assessment and an associated dose registry is currently a national issue, but exposed workers are active internationally, therefore their personal dose values must be combined into a single value. This is only possible if dose assessment is performed in each country with the same level of reliability and if combining dose values is done based on harmonised data processing.

The EMN established in 2021 will provide the base to implement and to guarantee the same metrological quality of radiation protection for all European citizens by harmonising procedures and combining the capabilities in service and research (i.e. calibration, type testing and reference fields with the vocabulary explained in VIM, 2012, and the requirements laid down in ISO/IEC 17025:2017, 2017). This requires a coordinated approach to ensure that the required metrological quality in the dissemination of the radiation protection quantities is reached for all dose assessments performed under the European regulation: The basic aim is to balance between the required redundancy whilst avoiding unnecessary duplication of work to free up resources to address the new technological needs.
The Technical Committee for Ionizing Radiation (TCIR) is EURAMET's committee for sharing and developing knowledge on the metrology of ionizing radiation, especially regarding the exchange of knowledge among the EURAMET member countries. It also aims to initiate research activities as well as to develop and maintain Calibration and Measurement Capabilities (CMCs). The now established EMN for Radiation Protection will extend the metrological capabilities and capacities in Europe towards non-National Metrology Institutes (non-NMIs) or non-Designated Institutes (nonDIs). This includes groups dealing directly with underpinning the EURATOM Treaty with environmental monitoring in Europe, passing their data on to the Joint Research Centre to be used in the European Radiological Data Exchange Platform (EURDEP) and the European Atlas of Natural Radiation (EANR), as well as groups underpinning the Council Directive (EU-BSS) in calibration, service and knowledge sharing of radiation protection organised under the European Radiation Dosimetry Group (EURADOS). The combined work will strengthen the cooperation at the European level, foster established cooperation and provide guidance for the further development of the metrological infrastructure through the preparation of an Strategic Research Agenda (SRA) and roadmaps.

The international bodies involved in this effort include international organisations, such as the International Atomic Energy Agency (IAEA) with the Secondary Standard Dosimetry Laboy (SSDL) and the Analytical Laboratories for the Measurement of Environmental Radioactivity (ALMERA) networks, the World Health Organisation (WHO), the Bureau International des Poids et Mesures (BIPM), the International Commission on Radiation Units and Measurements (ICRU), the International Commission on Radiological Protection (ICRP), the International Committee for Radionuclide Metrology (ICRM) and standardisation bodies, such as the International Organization for Standardization (ISO) with TC 85 (Technical Committee 85: Nuclear energy, nuclear technologies, and radiological protection) and the Comité Européen de Normalisation (CEN), the International Electrotechnical Commission (IEC) with TC 45 (Nuclear instrumentation) and the Comité Européen de Normalisation Électrotechnique (CENELEC) which provide guidance in the field on radiation risks, dose assessment, technical and metrological state of the art, but do not link the metrology directly to the needs expressed in regulation. This direct link can be established by the EMN. The EMN will work on coherence procedures in calibration and type testing according to international standards such as those developed by IEC and ISO. This supports the development of all types of equipment (sources, detectors, dosimeters) in a harmonised market which is growing rapidly. With the introduction of shared specialised facilities, it will become possible to secure the protection goal without driving up costs for the member states. A quite simple example is the availability special infrastructure like a low-level underground laboratory 
with a well characterized irradiation facility, which is fundamental for environmental dosimetry (Röttger and Kessler, 2019). This is clearly an infrastructure that is not needed in every member state. In summary it could be a solution to finance different specialized facilities nationally. Without the need to duplicate the whole metrology infrastructure the costs will go down for each member state and the service income will increase: By pooling customers, a business model for national institutes is created.

\section{Organisation of work}

The goal of the network project is a harmonized, sustainable, coordinated and intelligently specialized infrastructure to support the needs expressed in the European Radiation Protection Ordinance (Council Directive 2013/59/Euratom, 2013; EURATOM Treaty, 2021). Such an EMN under the umbrella of EURAMET has been founded now and is accompanied in parallel by the EMPIR project 19NET03 supportBSS with five technical work packages (WP) explained in the following sub sections:

\subsection{Implementing a long-term dialogue}

The aim of the first work package is to establish regular, constructive dialogue and liaison between the network project and stakeholders of radiation protection regulation. The stakeholder needs are central to the development of all work packages, see Fig. 1.

An on-line questionnaire to identify existing metrological capabilities related to radiation protection, stakeholders and their needs was created and sent to the identified stakeholders. The stakeholders included standards development and regulatory organizations, national and international bodies, manufacturers of radiation protection devices, medical staff, etc. A Stakeholder committee was formed from the identified Stakeholder groups. The available information from the international organisations on Strategic Research Agendas (SRAs), strategic agendas (SAs) and roadmaps was collected and summarized for a stakeholder review. A database including information on stakeholders was created and will be updated regularly throughout the project.

\subsection{Web portal for radiation protection regulation}

The aim of the second work package is to design and implement a web portal serving as a contact point for the metrology community, stakeholders and customers in the area of radiation protection and enabling them easy access to capabilities and the ability to interact and exchange information.

Main work effort is planned for this work package in 2021. First phase of the project is relying on the stakeholder pool created and on information gathered from the stakeholders. Until now, a summary of the presentation of a web portal for communication between the members, partners and users

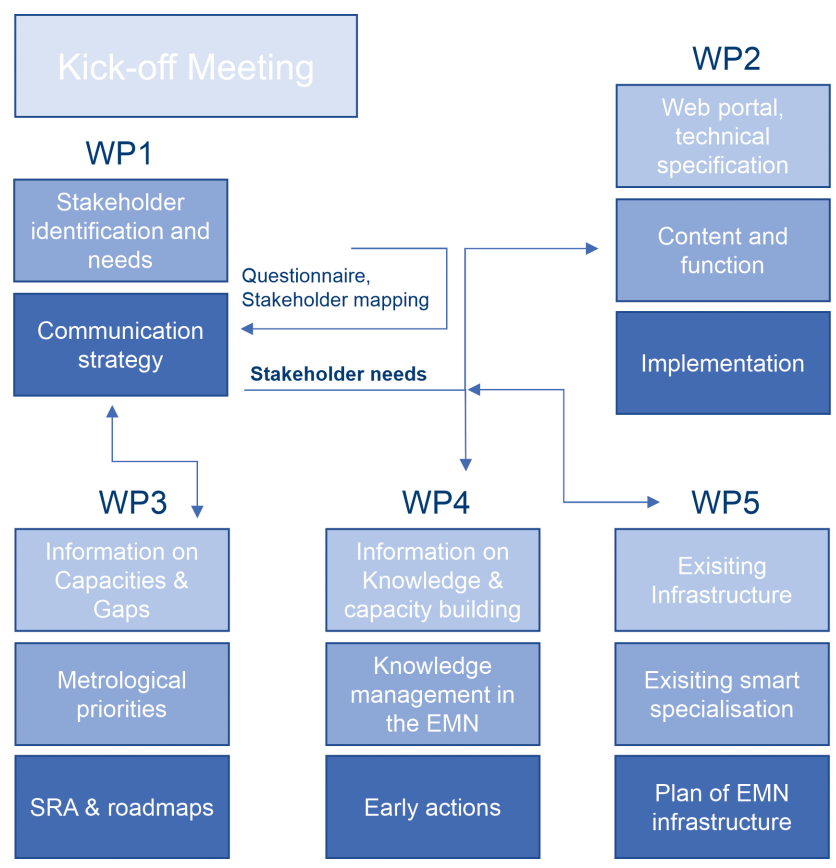

Figure 1. The work packages (WP) in EMPIR 19NET03 supportBSS. The figure describes the route for the implementation of the EMN for Radiation Protection. The Stakeholder needs are central for all work packages.

was created. At present, a proposal of future web portal administration requirements addressing e.g. the accessibility of web portal, procedure of validation of published information is being prepared to be discussed and decided by the consortium.

\subsection{Strategic Research Agenda (SRA) and Roadmaps}

The aim of the third work package is to develop a Strategic Research Agenda (SRA) and roadmaps for metrology services underpinning radiation protection regulation. This task started with the study of the SRA and equivalent strategic documents produced by the radiation protection platforms e.g. Multidisciplinary European Low Dose Initiative (MELODI), European Radiation Dosimetry Group (EURADOS), European Alliance for Medical Radiation Protection Research (EURAMED), European Platform on preparedness for nuclear and radiological emergency response and recovery (NERIS), European Radioecology Alliance (ALLIANCE) and Social Sciences and Humanities in Ionising Radiation Research (SHARE), as well as relevant organizations such as the EURAMETs TC-IR, IAEA, BIPM, Heads of Radiation Protection Authorities (HERCA), among other, looking for the identification of research needs and trying to establish a link to metrology issues. The perspective of each platform and organization in each specific field together with the fundamental or applied research character of the topic, its relative importance if identified by more than one, was noted. 
A draft document providing a summary of the main findings is currently in circulation among the project partners and will be used later for a focused discussion with the stakeholders. Their inputs and suggests will form the basis to produce an SRA with a gap analysis and identified priorities for metrology.

\subsection{Knowledge-sharing and capacity building}

The aim of the fourth work package is to develop a knowledge-sharing programme that promotes the transfer of knowledge from NMI/DIs to stakeholders (primarily emerging NMIs/DIs, secondary calibration laboratories and radiation protection workers). It is envisaged that the knowledgesharing and capacity building programme will include regularly hosted activities for a wide range of stakeholders, such as the exchange of scientific personnel between organisations, metrology workshops, training courses and interlaboratory comparisons.

An online literature review has been completed to assess the current availability of radiation protection training courses, capacity building activities and other knowledgesharing activities. The main points identified here were in the field of metrological competence (type testing, calibration, uncertainty calculation and conducting comparisons) and radiological emergency response. Radiation protection metrology requires specific competences, which are, however, not well defined. Moreover, the verification of the competence is not consistent. It was concluded that there is a need to harmonize the qualification of radiation metrologists on a national/international level.

This information will feed into a future gap-analysis with the intention of identifying where knowledge transfer activities are required. One early example is the guidance that consortium members (and colleagues from EMPIR Preparedness) are providing to "citizen science" networks who are interested in making their own radiation measurements. Such networks, though not providing services to support radiation protection regulation, are playing an increasingly important role in environmental radiation protection.

\subsection{Joint and sustainable European metrology infrastructure}

The aim of the last technical work package is to develop a plan for a joint and sustainable European metrology infrastructure underpinning radiation protection regulation. The plan was successfully completed within the first 12 months of the project and addresses how to (i) use coordination and smart specialisation of capabilities (European Commission, 2021), (ii) align with other running initiatives and projects, (iii) promote the development of emerging member states, and (iv) consider how to extend collaboration to third countries.
In the first steps, the existing metrology infrastructure that underpins the radiation protection regulation has been identified and combined into a data base. The available good practice guidelines and international standards (ISO, IEC) and IAEA guidelines related to radiation protection calibrations, type testing and emergency preparedness have been collected as well and have been combined in a second data base. From these data, a gap analysis will be performed to identify the fields of radiation protection where infrastructure, guidelines and standards are missing. Further information is available in the newsletter of EMPIR 19NET03 supportBSS 2021 (https://www.euramet.org/index.php?eID= tx_securedownloads $\& \mathrm{p}=418 \& \mathrm{u}=0 \& \mathrm{~g}=0 \& \mathrm{t}=1668514125 \&$ hash=7d4f98b29a6b19f1b51ca4f04c5fca131f18341e\& file=Media/images/projects_EMRP_EMPIR_Partnership/ Networks/19NET03/supportBSS_Project_Overview_2021_ 03_15.pdf, last access: 15 September 2021) and EURAMETs' official Website (https://www.euramet.org/ european-metrology-networks/radiation-protection/, last access: 15 September 2021).

\section{Early results and conclusion}

A virtual workshop on gaps in radiation protection metrology was held on 11 September 2020. It was organized by the consortium of 19NET03 supportBSS. Gaps in radiation protection metrology and capacities either in the scope of the Council Directive 2013/59/EURATOM or in aspects of the EURATOM Treaty were discussed and summarized in six parallel sessions. The topics considered most important in terms of radiation protection metrology were summarized in six main categories: Reference fields, radiation protection quantities, education and training needs, measurement devices for radiation protection in medical or industry applications of ionizing radiation or for environmental monitoring and handling and transmission of measurement data, activity standards, and type testing including harmonisation of the national requirements by radiation protection legislation, ISO standards and accreditation. A summary report on the workshop was distributed to all participants and published later (Khanbabaee et al., 2021). A Comité consultatif des rayonnements ionisants (CCRI) webinar on "Metrology for Radiation Protection" was run on 5 October 2020 by the coordinator of supportBSS. This webinar summarized the technical issues that need to be tackled for the coming years for example photon fields with high energies, epithermal neutron reference fields and radon metrology. It showed new approaches including opportunities to get involved in environmental research using natural sources of ionizing radiation. The second part of the webinar covered a EURAMET initiative to engage with stakeholders and to strengthen existing knowledge transfers. This BIPM webinar is available on YouTube (https://www.youtube.com/watch?v=V2B77LyY62I, last access: 15 September 2021). 


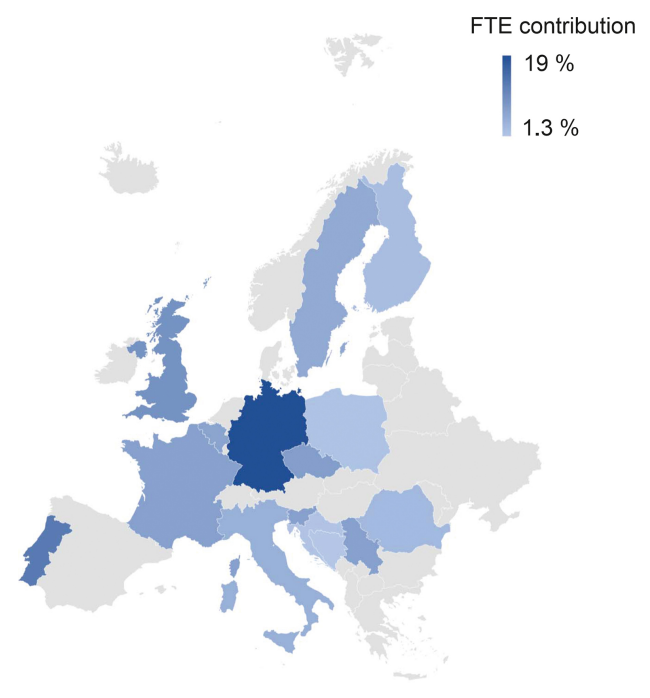

Figure 2. European map of the EMN for Radiation Protection. Relative staff power per member state in terms of full-time-equivalent (FTE) persons from the foundation phase. In total more than 200 FTEs have been assigned. This is value is used to represent relative contribution in colour code.

The EMN will spread over Europe as interested members and partners committed themselves to provide input by their capacities in terms of full-time-equivalent (FTE) persons to the mission of EMN for Radiation Protection, see Fig. 2. Overall, this results to a number of more than 200 FTE.

Fostering the mutual exchange of expert knowledge in the EMN will not only identify routes for innovative metrology but may also provide input for legal processes, feedback to the legislation, standardisation and common research activities directly responding to European legal requirements as addressed in the report of the Norwegian Radiation Protection Authority 2017 (Norwegian Radiation Protection Authority, 2017).

It is important for the successful implementation of the EMN that all fields where ionizing radiation is used are well represented. This involves the need to raise the awareness on this powerful new structural element under EURAMET e.V. For example, the rising interest to use natural radioactivity and natural radiation in environmental science triggers the need for services that the network can support: For new developments in environmental monitoring, research in geophysics and in climate observation, see A. Röttger et al. (2021) and S. Röttger et al. (2021).

Overall, the population will be more effectively protected against dangers arising from ionising radiation and the public confidence in the decisions of national governments will be significantly increased with a EMN for radiation protection in operation. Because social peace depends on public confidence in government decisions, the EMN for Radiation Protection will directly support the aim of the European Union: To promote peace and the well-being of EU citizens.
Data availability. The authors confirm the the data supporting the findings of this publication are available in the references given or in case of the SRA available on the SharePoint for the EMN for Radiation Protection. Data on SRA is available from the corresponding author upon reasonable request.

Author contributions. AR form PTB drafted the outline of the manuscript with contributions from all co-authors. The text was prepared by her and edited jointly. All co-authors provided significant input according to their expertise, especially: AS is responsible fpr WP1, VS for WP2, JHGA manages WP3, SB handels WP4, RN is managing WP6, while the WP5 and WP7 is in the responsibility of PTB.

Competing interests. The contact author has declared that neither they nor their co-authors have any competing interests.

Disclaimer. Publisher's note: Copernicus Publications remains neutral with regard to jurisdictional claims in published maps and institutional affiliations.

Special issue statement. This article is part of the special issue "Geoscience applications of environmental radioactivity (EGU21 GI6.2 session)". It is a result of the EGU General Assembly 2021, 19-30 April 2021.

Acknowledgements. The consortium is grateful to have this powerful support from colleagues worldwide! Further collaboration interest is welcome as stated in the supportBSS newsletter. The partners of the project received support from BIPM, IAEA, EURADOS e.V., $\mathrm{BfS}$ and PHE so far. BfS became a partner already, and it is foreseen that EURADOS e.V., and PHE will join the EMN as partners, too. They were included as authors to the proposal for the GA of EURAMET in 2021 and intend to sign the memorandum of understanding as well as all supportBSS partners, which are represented here as co-authors of this paper.

This project 19NET03 supportBSS has received funding from the EMPIR programme co-financed by the Participating States and from the European Union's Horizon 2020 research and innovation programme. 19NET03 supportBSS denotes the EMPIR project reference.

Financial support. This project 19NET03 supportBSS has received funding from the EMPIR programme co-financed by the Participating States and from the European Union's Horizon 2020 research and innovation programme. 19NET03 supportBSS denotes the EMPIR project reference.

This open-access publication was funded by the Physikalisch-Technische Bundesanstalt. 
Review statement. This paper was edited by Virginia Strati and reviewed by two anonymous referees.

\section{References}

Bossew, P.: Radon priority areas - definition, estimation and uncertainty, Nuclear Technology and Radiation Protection, 33, 11-11, https://doi.org/10.2298/NTRP180515011B, 2018.

Clarke, R. H. and Valentin, J.: The history of ICRP and the evolution of its policies, ICRP Publication 109, Ann. ICRP, 39, 75-110, https://doi.org/10.1016/j.icrp.2009.07.009, 2009.

Council Directive 2013/59/Euratom: Council Directive 2013/59/Euratom of 5 December 2013 laying down basic safety standards for protection against the dangers arising from exposure to ionising radiation, CELEX number: 32013L0059, available at: https://eur-lex.europa.eu/legal-content/EN/TXT/ ?uri=CELEX:32013L0059 (last access: 15 September 2021), 2013.

EURATOM Treaty: Treaty establishing the European Atomic Energy Community, established the European Atomic Energy Community, signed on 25 March 1957. CONSOLIDATED VERSION, ISBN 978-92-824-5085-7, available at: https://eur-lex.europa.eu/legal-content/DE/TXT/?uri=CELEX: 12012A/TXT, last access: 5 October 2021.

European Commission: SMART SPECIALISATION PLATFORM, available at: https://s3platform.jrc.ec.europa.eu/, last access: 15 September 2021.

IAEA: INTERNATIONAL ATOMIC ENERGY AGENCY, Occupational Radiation Protection, IAEA Safety Standards Series No. GSG-7, IAEA, Vienna, available at: https://www.iaea.org/topics/ workers (last access: 15 September 2021), 2018.

IAEA: INTERNATIONAL ATOMIC ENERGY AGENCY, Protection against Exposure Due to Radon Indoors and Gamma Radiation from Construction Materials - Methods of Prevention and Mitigation, IAEA-TECDOC-1951, IAEA, Vienna, 2021.

ICRP: The International Commission on Radiological Protection 80th Anniversary: The evolution of its policies through 80 years, in: Strengthening Radiation Protection Worldwide, edited by: Gallego, E., Pérez, M., and Beatriz, G., IRPA XII Congress, available at: https://www-pub.iaea.org/MTCD/ publications/PDF/Pub1460_web.pdf, last access: 15 September 2009.

ISO/IEC 17025:2017: General requirements for the competence of testing and calibration laboratories, ISO, Geneva, 2017.

Jarvis, D.: Progress on developing EMNs, 14 December 2018, Berlin Workshop, EUREMAT e.V., Braunschweig, 2018.

Khanbabaee, B., Röttger, A., Behrens, R., Röttger, S., Feige, S., Hupe, O., Zutz, H., Toroi, P., Leonard, P., de la Fuente Rosales, L., Burgess, P., Gressier, V., Gutiérrez Villanueva, L.-J., Cruz Suárez, R., and Arnold, D.: Support for a European metrology Network on reliable radiation protection: Gaps in radiation protection metrology, RAD Conference Proceedings, Vol. 5, 1-4, https://doi.org/10.21175/rad.abstr.book.2021.31.8, 2021.
Norwegian Radiation Protection Authority: Ionising radiation metrology infrastructure in Europe. A survey in European counties' regulations about IR metrology regulations and calibration requirements in radiation protection legislation. Ionising radiation metrology infrastructure in Europe, Report number: 2017:2, available at: https://www.euramet.org/index.php?eID=tx securedownloads $\& \mathrm{p}=529 \& \mathrm{u}=0 \mathrm{~g}=0 \& \mathrm{t}=1666259121 \& \mathrm{hash}=$ e148bce3fbd4e39ee56cfd13f5934089c3dc6dd4\&file=Media/ docs/projects/EURAMET-P1284_IONRAD_Final_Report.pdf (last access: 15 September 2021), 2017.

OECD: "Urban population in OECD countries", in: OECD Regions at a Glance 2013, OECD Publishing, Paris, https://doi.org/10.1787/reg_glance-2013-6-en, 2013.

Röttger, A. and Kessler, P.: Uncertainties and characteristic limits of counting and spectrometric dosimetry systems, J. Environ. Radioactiv., 205-206, 48-54, https://doi.org/10.1016/j.jenvrad.2019.04.012, 2019.

Röttger, A., Röttger, S., Mertes, F., Kartens, U., Gruber, V., and Levin, I.: Radon: Das Schöne und das Biest, Strahlenschutzpraxis 2, 60-68, 2021.

Röttger, S., Röttger, A., Grossi, C., Karstens, U., Cinelli, G., and Rennick, C.: Radon metrology for use in climate change observation and radiation protection at the environmental level, EGU General Assembly 2021, online, 19-30 April 2021, EGU21-173, https://doi.org/10.5194/egusphere-egu21-173, 2021.

Södersten, A.: Euratom at the Crossroads, Edward Elgar Publishing, Cheltenham, ISBN: 978-1-7881-1224-6, https://doi.org/10.4337/9781788112253, 2018.

Stanley, F. K. T., Irvine, J. L., and Jacques, W. R.: Radon exposure is rising steadily within the modern North American residential environment, and is increasingly uniform across seasons, Sci. Rep. UK, 9, 18472, https://doi.org/10.1038/s41598-019-548918, 2019.

StrlSchV: Verordnung zum Schutz vor der schädlichen Wirkung ionisierender Strahlung (Strahlenschutzverordnung - StrlSchV), StrlSchV, Ausfertigungsdatum: 29 November 2018, BGB1. I S. 2034, 2036, 2018.

UNEP: Radiation: effects and sources, United Nations Environment Programme, ISBN: 978-92-807-3517-8, available at: https:// www.unscear.org/unscear/en/publications/booklet.html (last access: 15 September 2021), 2016.

UNSCEAR Report: Sources and effects of ionizing radiation, United Nations publication, Herndon, 2008.

VIM: Joint Committee for Guides in Metrology: International vocabulary of metrology - Basic and general concepts and associated terms (VIM), JCGM, Paris, https://doi.org/10.1515/ci.2012.34.3.26, 2012. 